\title{
STUDY OF DYNAMIC BUCKLING OF FG PLATE DUE TO HEAT FLUX PULSE
}

\author{
L. CZECHOWSKI \\ Department of Strength of Materials \\ Lodz University of Technology \\ 90-924 Łódź, ul. Stefanowskiego 1/15, POLAND \\ leszek.czechowski@p.lodz.pl
}

\begin{abstract}
The paper deals with a FEM analysis of dynamic buckling of functionally graded clamped plates under heat flux loading with huge power. The materials of structures as well as their properties are varying in each layer across the plate thickness formulated by the power law distribution. The heat flux was applied evenly to the whole ceramic surface. The analysis was developed in the ANSYS 14.5 software. The duration of the heat flux loading equal to a period of natural fundamental flexural vibrations of given structures was taken into consideration. To implement large deflections of structures, the Green-Lagrange nonlinear-displacement equations and the incremental Newton-Raphson algorithm were applied. An evaluation of the dynamic response of structures was carried out on basis of the Budiansky-Hutchinson criterion. The studies were conducted for different volume fraction distributions and different shapes of the heat flux loading. The computation results of the heat flux versus maximal plate deflection are shown and discussed.
\end{abstract}

Key words: dynamic buckling, heat flux, finite element method, FGMs, ceramics.

\section{Introduction}

The first concept of functionally graded materials (FGMs) was proposed in 1984 by scientists in Japan. Since that time high heat-resistant materials using functionally graded know-how have been developed until today. FGMs comprise a mixture of metal and ceramics in different proportions in order to achieve proper characteristics. Material properties continuously change from one surface to another, excluding an appearance of some problems, concentration of thermal stresses, among others. These materials are microscopically heterogeneoues and can be manufactured from isotropic constituents mostly such as metals and ceramics. Due to low thermal conductivity of ceramics, FGMs can be applied in the ultrahigh temperature environment such as nuclear plants, aerospace, thermal ballistic shields or space vehicles, etc. The ceramic material can withstand immensely high temperatures (above $2000 \mathrm{~K}$ ) whereas metal is responsible for the strength component ensuring a constituent structure.

Taking a look at literature concerning FGMs, many analyses have been pursued and described. Tung and Duc (2010) presented a simple analytical approach to the investigation of the functionally graded plate stability under in-plane compressive, thermal and combined loads. They assumed temperature-independent material properties graded in the thickness direction. The problem was solved using the classic plate theory. $\mathrm{Na}$ and Kim (2005) conducted the thermal buckling and postbuckling analyses for FGMs up to a uniform and non-uniform temperature rise, applying the finite element method. In the calculations, they used the GreenLagrange nonlinear strain-displacement relation for large deflections. Javaheri and Eslami (2012), on the basis of a higher order shear deformation plate theory, examined the stability of the functionally graded plate under thermal loads. They took four types of thermal loads into consideration and compared their results of buckling loads to the classic plate theory ones accessible in the literature. It was stated that the CPT overestimated the buckling temperature. The post-buckling response of the functionally graded material plate subjected to thermal and mechanical loading was studied by $\mathrm{Wu}$ et al. (2007). The researchers assumed 
different types of boundary conditions based on the first-order shear deformation theory and von Karman nonlinear kinematics. Bodaghi and Saidi (2010) investigated buckling of thick functionally graded plates. They converted the governing stability equations into uncoupled partial differential equations and obtained the results using the Levy-type solution. Samsam Shariat, Javaheri and Eslami (2005) presented the analysis of FG plates with different geometrical imperfections. On the other hand, in the literature we can find many papers devoted to studies of the structure response under in-plane pulse loading of finite durations (dynamic analysis). Praveen and Reddy (1998) studied the static and dynamic response of the functionally graded material with different volume fraction. The FG plates were subjected to temperature field. Czechowski and Kowal-Michalska (2013) analysed the buckling phenomenon for static and dynamic loading (pulse of finite duration) of functionally graded plates subjected to uniform temperature increment. They investigated FG structures for different values of volume fraction index and uniform temperature rise in the form of a rectangular pulse of finite duration. Jankowski and Kowal-Michalska in (2013) examined a simply supported squared girder subjected to various thermal pulse loadings. They analysed an influence of different types of pulse load, initial imperfection and time on dynamic buckling behavior.

Kowal-Michalska (2007), Mania and Kowal-Michalska (2007), Kowal-Michalska and Mania (2007), Mania (2011) and Volmir (1972) investigated the behaviour of different structures made of isotropic, orthotropic or composite materials. In these works, it has been also ascertained that dynamic buckling occurred for pulses of the intermediate amplitudes when the duration of dynamic load was close to a period of the natural flexural vibrations of the given structure. As far as dynamic buckling is concerned, damping effects do not have a significant influence upon structure responses. In comparison to static buckling, dynamic buckling appears only for structures with initial deflections because the dynamic buckling load of bifurcational type does not exist.

In the present analysis accomplished on basis of the finite element method, functionally graded plates subjected to the heat flux pulse are examined. Furthermore, different distributions of material inwards the plate according to the power law distribution index are taken into consideration. In the transient analysis, a plate composed of solid elements with varying material properties in each layer is considered. Calculations are carried out incrementally using the Newton-Raphson convergence approximation method. The pulse duration is equal to one period of the natural flexural vibrations of the given structure with different material properties distribution across the plate thickness. In this investigation, different shapes of the heat flux pulse on the whole ceramic surface are examined.

\section{Material description}

The plates considered in this work were built of continuously varying material properties across the thickness direction. On the bottom surface of the plate, a pure metal is taken and it grades finally to the top surface composed of ceramics only. The volume fractions of two materials in this case metal $V_{m}$ and ceramics $V_{c}$ have been formulated through a power law distribution Eqs. (2.1) and (2.2).

$$
\begin{aligned}
& V_{m}(z)=\left(1-\frac{z}{h}\right)^{n}, \\
& V_{c}(z)=1-V_{m}(z)
\end{aligned}
$$

where $n(n \in<0, \infty)$, if $n=0$ - pure metal; if $n=\infty$ - pure ceramics) represents the material variation distribution index across the plate thickness (marked by $h$ ). A volume fraction of ceramics and metal in a function of the distribution index across the plate thickness is plotted in Fig.1. The material properties $P(z)$ in relation to the layer position through the plate thickness are expressed as follows 


$$
P(z)=P_{m} \cdot V_{m}(z)+P_{c} \cdot V_{c}(z)=P_{c}+\left(P_{m}-P_{c}\right) \cdot\left(1-\frac{z}{h}\right)^{n}
$$

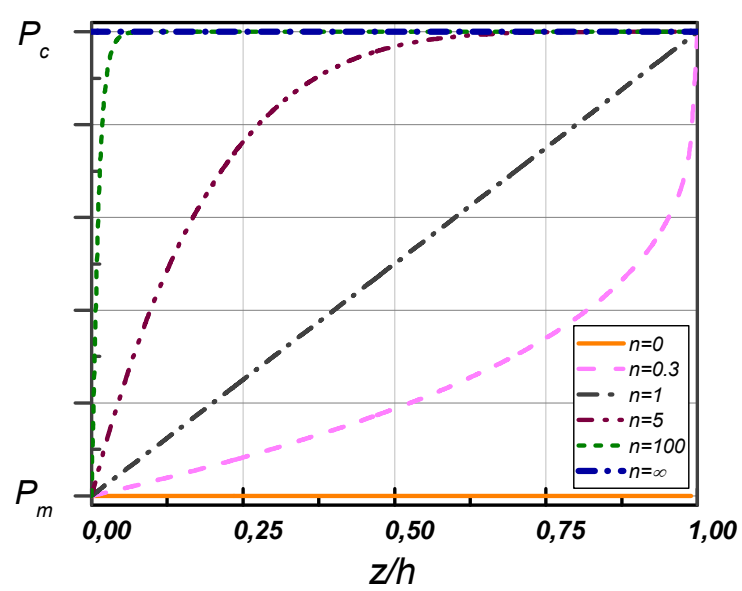

Fig.1. Volume fraction of ceramics and metal dependent on the distribution index across the plate thickness.

\section{Numerical models}

Generally, the relations between stresses and strains can be written as

$$
\{\sigma\}=[D] \cdot\left\{\varepsilon^{e l}\right\}
$$

where $\{\sigma\}=\left[\begin{array}{llllll}\sigma_{x} & \sigma_{y} & \sigma_{z} & \tau_{x y} & \tau_{y z} & \tau_{x z}\end{array}\right]^{T}$ denotes the stress vector, $D$ - stiffness matrix and $\left\{\varepsilon^{e l}\right\}=\{\varepsilon\}-\left\{\varepsilon^{\text {th }}\right\}$ elastic strain vector, respectively. The total strain vector and the thermal strain vector are expressed by

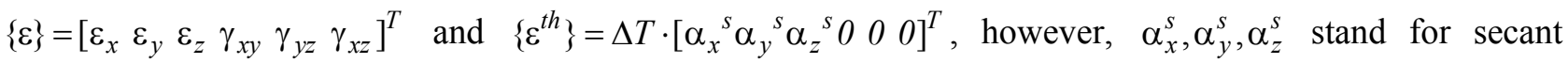
coefficients of the thermal expansion and $\Delta T$ is an increase and a decrease in temperature.

The equation of the principle of virtual work is as follows (Documentation for Ansys)

$$
\delta U=\delta V
$$

where $U=U_{1}+U_{2}$ and $V=V_{1}+V_{2}+V_{3}$ demonstrate the strain energy (internal work) and the external work, respectively. The virtual strain energy is composed of $\delta U_{l}=\int_{V o l}\{\delta \varepsilon\} \cdot\{\sigma\} \cdot d V o l^{T}$ and $\delta U_{2}=\int_{A}\left\{\delta w_{n}\right\}^{T} \cdot\{\sigma\} \cdot d A$ (in the case when a surface opposes due to the external pressure), where the quantities mean: Vol - volume of the element , $w_{n}$ - motion normal to the surface, $A$ - area of the element. The external energy consists of a factor concerning acceleration (d'Alembert force vector), a factor determining the pressure force vector and, finally, a factor representing external forces related to nodal forces. Hence, the total external virtual work for finite elements has the following form

$$
\delta V=-\{\delta u\}^{T} \cdot \rho \int_{V o l}[N]^{T} \cdot[N] \cdot d V o l \cdot \frac{\delta^{2}\{u\}}{\delta t^{2}}+\{\delta u\}^{T} \cdot \int_{A_{p}}\left[N_{n}\right] \cdot\{P\} \cdot d A_{p}+\{\delta u\}^{T} \cdot\left\{F_{e}^{n o d}\right\}
$$


where: $\rho$-density, $t$-time, $[N]-$ matrix of the shape functions, $\{P\}-$ applied pressure vector, $\left[A_{p}\right]-$ whole area on which the pressure acts, $\left[N_{n}\right]-$ matrix of the shape functions for normal motions at the surface, $\left\{F_{e}^{n o d}\right\}$-nodal forces applied to the element. Finally, if one inserts the relations $\{\sigma\}=k \cdot\left\{w_{n}\right\}=k \cdot\left[N_{n}\right] \cdot\{u\}$ and $\{\varepsilon\}=[B] \cdot\{u\}$ into the strain energy, where $k$ denotes foundation stiffness, $[B]$ - strain-displacement matrix, and $\{u\}$ - nodal displacement vector and next, noticing that the $\{\delta u\}^{T}$ vector is determined by the same arbitrary virtual displacements, then after some reductions, Eq.(3.3) can be written as

$$
\left(\left[K_{e}\right]+\left[K_{e}^{f}\right]\right) \cdot\{u\}-F_{e}^{t h}=\left[M_{e}\right] \cdot\{\ddot{u}\}+\left\{F_{e}^{p r}\right\}+\left\{F_{e}^{n d}\right\}
$$

where

$\left[K_{e}\right]=\int_{V o l}[B]^{T} \cdot[D][B] \cdot d V o l-$ element stiffness matrix,

$\left[K_{e}^{f}\right]=k \cdot \int_{A}\left[N_{n}\right]^{T} \cdot[N] \cdot d A$ - element foundation stiffness matrix,

$\left[F_{e}^{\text {th }}\right]=k \cdot \int_{V o l}[B]^{T} \cdot[D] \cdot\left\{\varepsilon^{t h}\right\} d V o l$ - element thermal load vector,

$\left[M_{e}\right]=\rho \cdot \int_{V o l}\left[N_{n}\right]^{T} \cdot[N] \cdot d V o l$ - element mass matrix,

$\{\ddot{u}\}=\frac{\partial^{2}\{u\}}{\partial t^{2}}-$ acceleration vector,

$\left[F_{e}^{p r}\right]=k \cdot \int_{A_{p}}\left[N_{n}\right]^{T} \cdot\{P\} \cdot d A^{p}$ - element pressure vector.

Referring to the first law of thermodynamics, the general equation can be written as

$$
\rho \cdot c \cdot\left(\frac{\partial T}{\partial t}+\{v\}^{T}\{L\} T\right)+\{L\}^{T}\{\dot{q}\}=\dddot{q}
$$

where $\rho, c, T, t,\{L\},\{v\},\{\dot{q}\}$ and $\{\dddot{q}\}$ denote density, specific heat, temperature $T=T(x, y, z, t)$, time, vector operator, velocity vector for mass transport of heat, heat flux vector, heat generation rate per unit volume, respectively.

The next relation concerns Fourier's law linking the heat flux vector to the thermal gradients and can be formulated as

$$
\{q\}=-[D]\{L\} T
$$

where $[D]$ represents conductivity matrix.

If one connects the above relations Eqs (3.5) and (3.6) and expands their form, the following equation is obtained

$$
\rho \cdot c \cdot\left(\frac{\partial T}{\partial t}+v_{x} \frac{\partial T}{\partial x}+v_{y} \frac{\partial T}{\partial y}+v_{z} \frac{\partial T}{\partial z}\right)=\dot{q}+\frac{\partial}{\partial x}\left(K_{x} \frac{\partial T}{\partial t}\right)+\frac{\partial}{\partial y}\left(K_{y} \frac{\partial T}{\partial t}\right)+\frac{\partial}{\partial z}\left(K_{z} \frac{\partial T}{\partial t}\right)
$$


where $K_{x}, K_{y}, K_{z}$ denote conductivity coefficients.

SOLID90 is a higher order version of the 3-D eight node thermal element (Fig.2). The element has 20 nodes with a single degree of freedom temperature at each node. The 20 -node elements have compatible temperature shapes and are well suited to model curved boundaries.

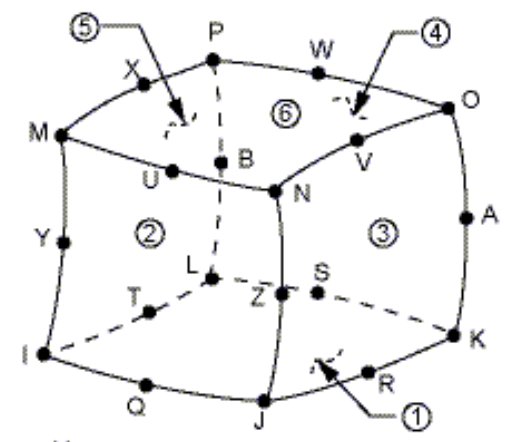

Fig.2. Finite element applied in simulation (solid 90-thermal and solid186-structural).

The 20-node thermal element is applicable to 3-D, steady-state or transient thermal analysis. solid186 is a higher order 3-D 20-node solid element that exhibits quadratic displacement behavior (a view of this element is the same as SOLID90 - see Fig.2). The element is defined by 20 nodes having three degrees of freedom at each node, namely translations in the nodal $x, y$, and $z$ directions (Documentation for Ansys). The element can be used for the plasticity, the hyperelasticity, the creep, the stress stiffening, large deflection and large strain capabilities. It also has combined formulation capability for simulating deformations of nearly incompressible elastic-plastic materials, and fully incompressible hyper-elastic materials.

The presented work deals with the plate of all clamped edges under thermal heat flux loading in a short time. The duration of pulse loading $t_{p}$ was equal to $1 t_{0}$, where $t_{0}$ is a period of natural fundamental flexural vibrations of the structure. In the studies, different pulse shapes were considered (see Fig. 3). Assumed shapes 2, 3, 4 have a equal area of energy and two times smaller than shape 1.

1)

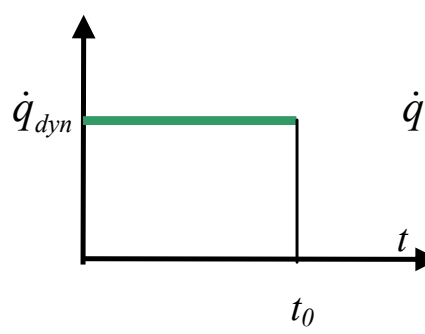

2)

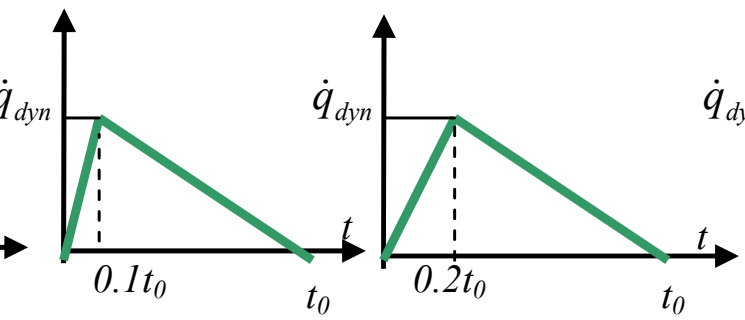

4)

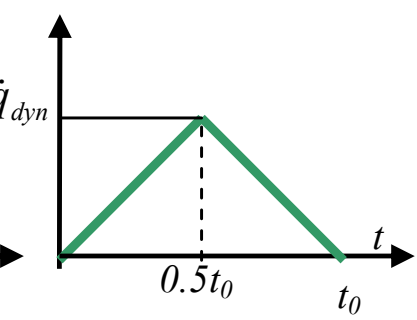

Fig.3. The shapes of heat flux pulses considered in studies.

Due to the possibility of greater deflections after the thermal load ceases, the observation of plate lasted always twice as long as the pulse duration.

Budiansky-Hutchinson (1966) introduced a factor called the Dynamic Load Factor (in abbreviation, $D L F$ ) and it can be determined in case of the heat flux load as 


$$
D L F_{\dot{q}}=\frac{\dot{q}_{d y n}}{q_{c r}^{\text {static }}}
$$

where following magnitudes demonstrate:

$\dot{q}_{d y n}$ - amplitude of the heat flux in MW,

$q_{c r}^{\text {static }}$ - critical buckling heat flux obtained in static buckling analysis for duration $t_{0}$.

According to accessible literature, some criteria of dynamic stability of thin-walled plate structures can be found. One part of criteria are based on the geometry entity (mainly, on the condition of reaching some deflection and shortening by the plate) or energy criteria relying upon potential or kinetic energy. Another criteria relate to the condition of the structure failure by reaching the maximal value of stress. Only few of them are shortly described below.

Volmir (1972) presented the simplest criterion of dynamic stability. It was suggested that the critical dynamic load is found if the plate deflection amounts to $1 h$ or $0.5 h$, where $h$ denotes the plate thickness.

Budiansky-Hutchinson (1966) implemented a criterion based on the state when the plate deflection grows rapidly at a small variation with a load.

\subsection{Boundary conditions and simulation conditions}

The investigations were performed for one type of structures, namely a square plate. The system of coordinates and the considered boundary conditions of the structure are presented in Fig.4. In all cases, dimensions of the plate were as follows: $a=1 \mathrm{~m}, b=1 \mathrm{~m}$, and thickness $h=0.01 \mathrm{~m}$.

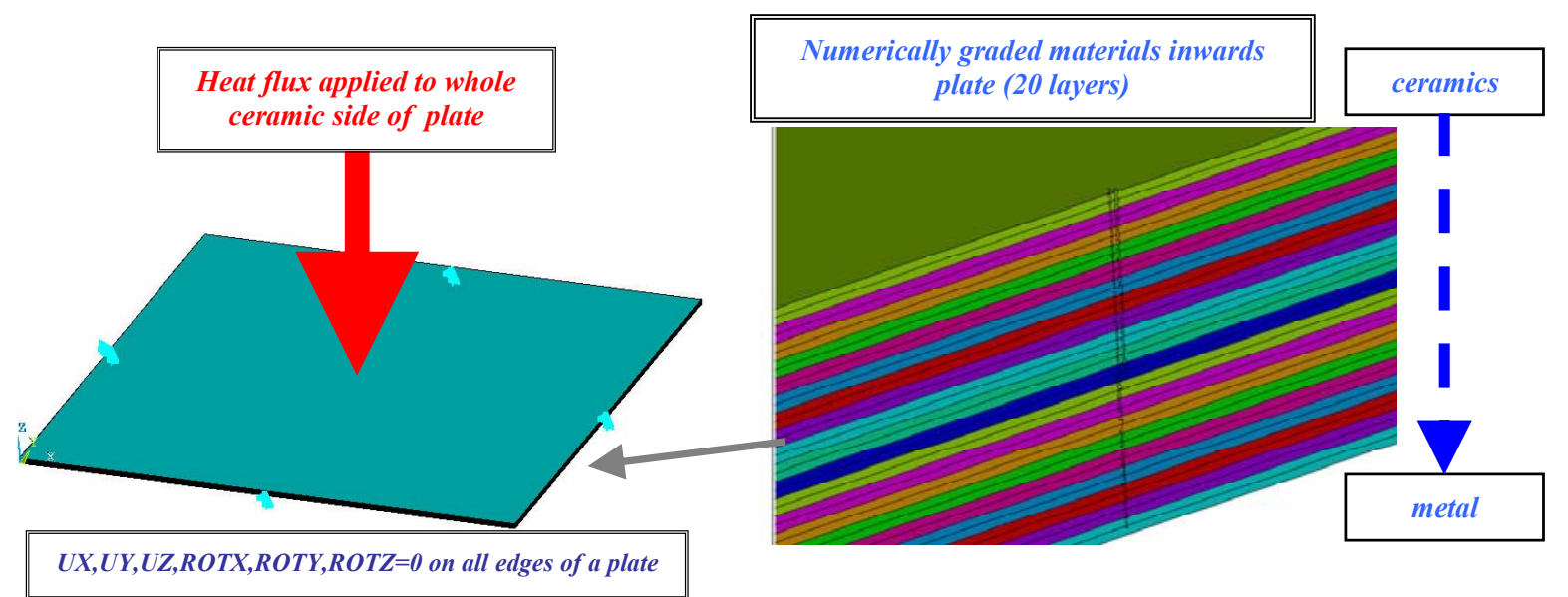

Fig.4. The numerical model of the clamped plate.

Numerical simulations were carried out in two separate analyses. In the first stage, it was important to calculate the natural flexural frequency for each plate with regard to $n$ distribution index. For found periods relating the natural flexural frequency for a given plate, the critical heat flux in static buckling analysis was determined (it allowed determining an amplitude of the heat flux). Afterwards, an adequate simulation for known time and amplitude (transient analysis of dynamic plate response under heat flux) was incrementally carried out. The computations were performed for different shapes of the heat flux without a damping coefficient (in the literature it was stated that for those durations damping is not of great importance). For all the plates, the initial deflection $w_{0}=0.01 \cdot h$ referring to the first buckling mode was taken into account. Simulation in the thermal scope under the heat flux pulse, was to determine the 
temperature distribution in the entire numerical model in the each step of the load duration. Further structural simulation was possible due to the temperature distribution application in the plate mesh what allowed obtaining interim stresses and displacements in the whole structure in the entire time. The observation of the structure behavior relied upon a record of maximal deflections of the plate throughout the simulation.

For the investigations, material properties for ceramics $\left(\mathrm{Al}_{2} \mathrm{O}_{3}\right)$ and metal $(\mathrm{Ni})$ for the FGM plate structures were assumed and are shown in Tab.1.

Table 1. Material properties of ceramics and metal.

\begin{tabular}{c|c|c}
\hline Materials properties & $\mathrm{Al}_{2} \mathrm{O}_{3}$ & $\mathrm{Ni}$ \\
\hline Young modulus [GPa] & 393 & 200 \\
\hline $\begin{array}{c}\text { Thermal expansion coefficient }[ \\
1 / \mathrm{K}]\end{array}$ & $13.3 \cdot 10^{-6}$ & $8.8 \cdot 10^{-6}$ \\
\hline Poisson ratio [-] & 0.25 & 0.3 \\
\hline Desity $\left[\mathrm{kg} / \mathrm{m}^{3}\right]$ & 3400 & 7800 \\
\hline $\begin{array}{c}\text { Thermal conductivity coefficient } \\
{\left[\mathrm{J} / \mathrm{m}^{*} \mathrm{~s}^{*} \mathrm{~K}\right]}\end{array}$ & 30 & 72 \\
\hline Specific heat $\left[\mathrm{J} / \mathrm{kg}^{*} \mathrm{~K}\right]$ & 880 & 460 \\
\hline
\end{tabular}

\section{Results and discussion of the numerical solution}

In this section, responses of the FGM plate clamped on its all edges under transient heat flux load are investigated. In the analysis, different volume fraction indexes and different shapes of the pulse were taken. The first diagram (Fig. 5) displays the temperature distributed inwards the plate thickness under rectangular heat flux pulse which can bring about the static buckling of the plate. Indeed, it can easily be observed that for a short time of the heat flux effect, the highest temperature appears on the side of the affected surface and rapidly drops to 0 in the plate depth of 0.15 thickness, regardless of a value of the volume fraction index. For $t_{p}=1 s$, if a small heat flux is applied, the obtained temperature distributions seem to be proportionally variable inwards the plate thickness and the value of the temperature starts from $150 \mathrm{~K}$ and decreases to almost $0 \mathrm{~K}$ on the metal side. For this case, because of the smaller heat flux pulse, the load duration can be pretty long and finally causes the flow of a heat throughout the plate thickness. Figures 6-10 illustrate the plate response under four considered pulse loads. In all cases, the pulse duration was equal to a period of natural flexural vibrations of a given plate. To assess the behavior of the dynamic buckling plate, the Budiansky-Hutchinson criterion was taken into consideration (see subsection 3.4). If the first shape is under investigation (found in the literature as the most dangerous - see Fig.3), it can be noticed that the full ceramic plate (for $n=\infty$ ) is most resistant to the heat flux load. In this case, the dynamic critical heat flux ranged from $78 \mathrm{MW}$ for $n=0$ to $190 \mathrm{MW}$ for $n=\infty$. For a clear view of the results of estimations, critical values of the heat flux and $D L F_{\dot{q}}^{c r}$ for all considered pulses are inserted in Tab. 2. If $D L F_{\dot{q}}$ for different distribution indexes was taken into account, it is simply noticed that all the curves have a similar course. When the plate losses dynamic stability (if $D L F_{\dot{q}}^{c r}$ is reached on the basis of the Budiansky-Hutchinson criterion), the deflections of the plate amount to below one thickness. If one takes a look at Fig. 6b, $D L F_{\dot{q}}^{c r}$ is equal to about $0.90 \div 0.98$. The next plots (Figs. $7 \mathrm{a}$ and $7 \mathrm{~b}$ ) deal with another pulse shape, namely shape 2 . Applying a triangular shape (pulse 2), the heat flux spanned from $220 \mathrm{MW}$ for $n=0$ to $480 \mathrm{MW}$ for $n=\infty$. 


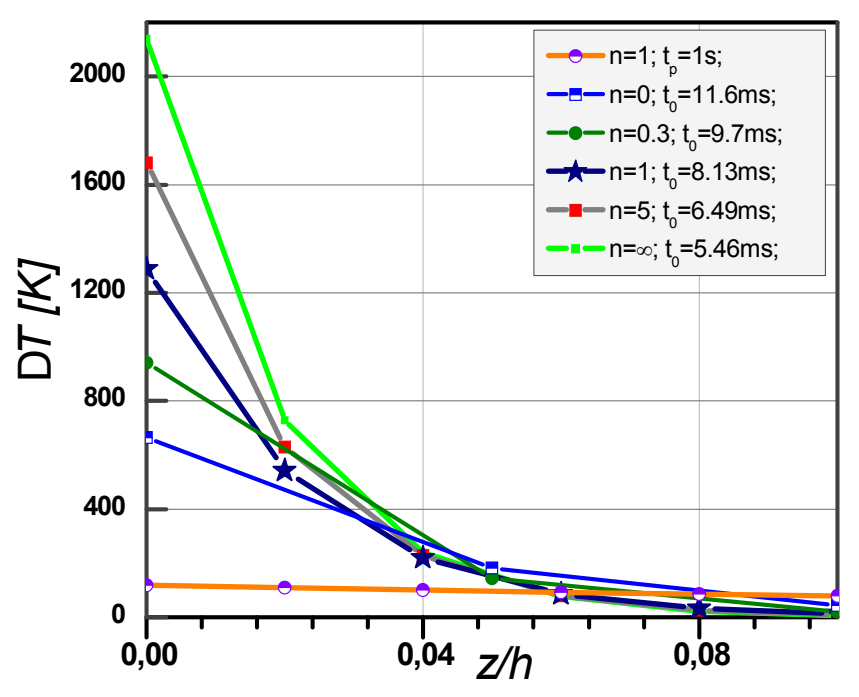

Fig.5. Temperature distribution across the plate thickness.

a)

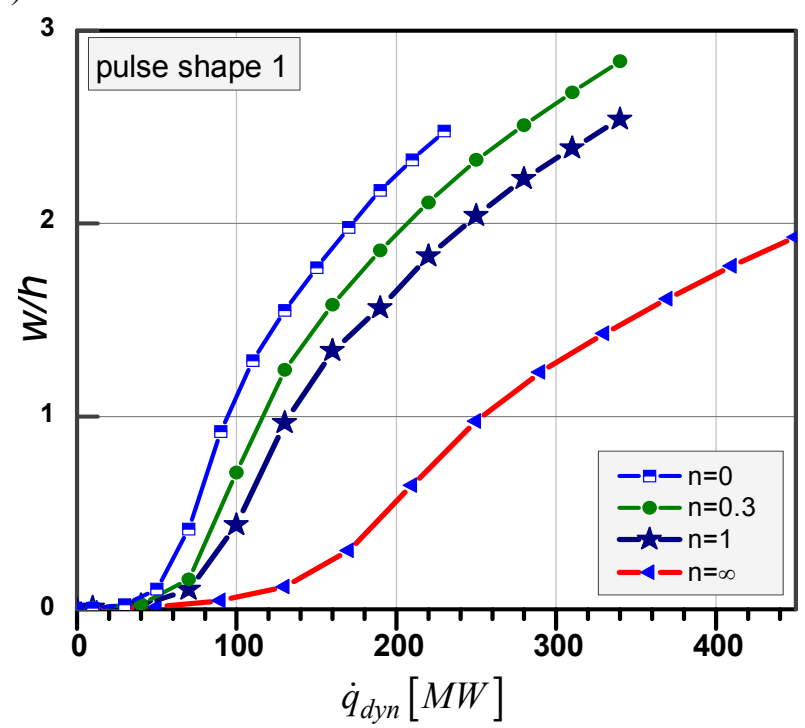

b)

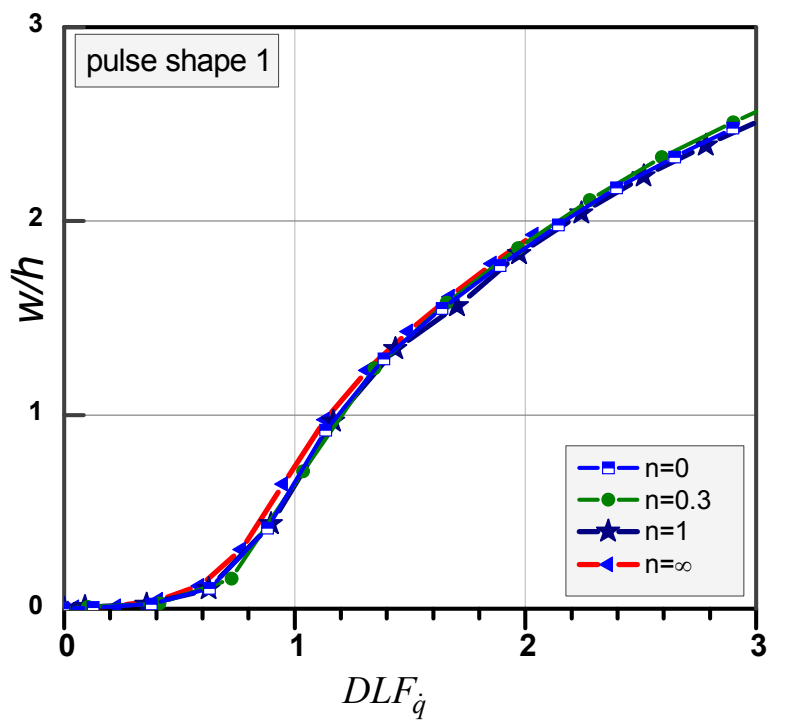

Fig.6. Maximal deflection of the plate versus a) dynamic heat flux load or b) $D L F_{\dot{q}}$ for different distribution indexes for shape 1.

As far as $D L F_{\dot{q}}^{c r}$ is concerned, the lowest value launches from 1.76 for $n=5$ up to 2.77 for $n=0$ (see Fig.7b). In comparison to previous curves for shape (Figs 6a and 6b), the received curves have a slightly other character. In the later one it was observed in some scope for all investigated distribution indexes the proportional growth of the plate deflection in function of the heat flux. Similarly, another pulse shape 3 causes comparative plate response as the pulse shape 2 and those both curves are almost the same (Figs 8a and $8 b)$. 
a)

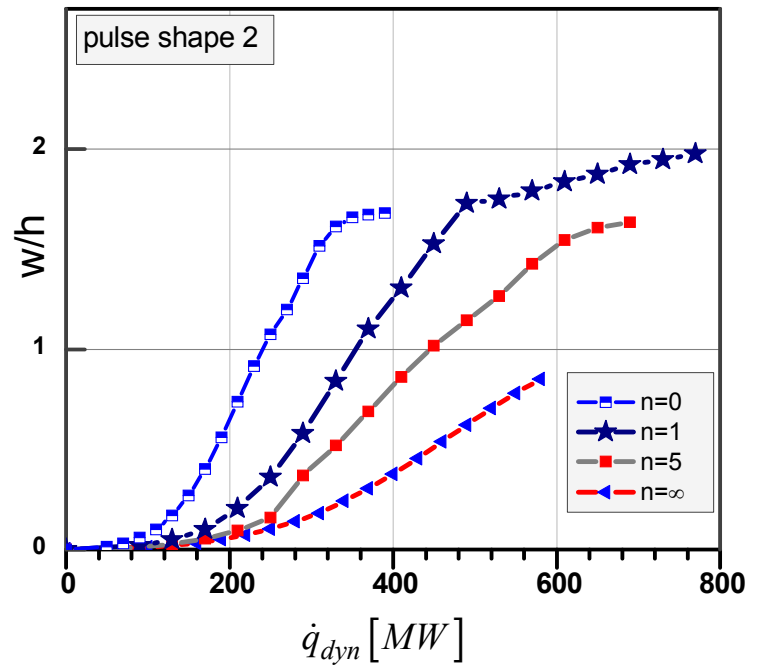

b)

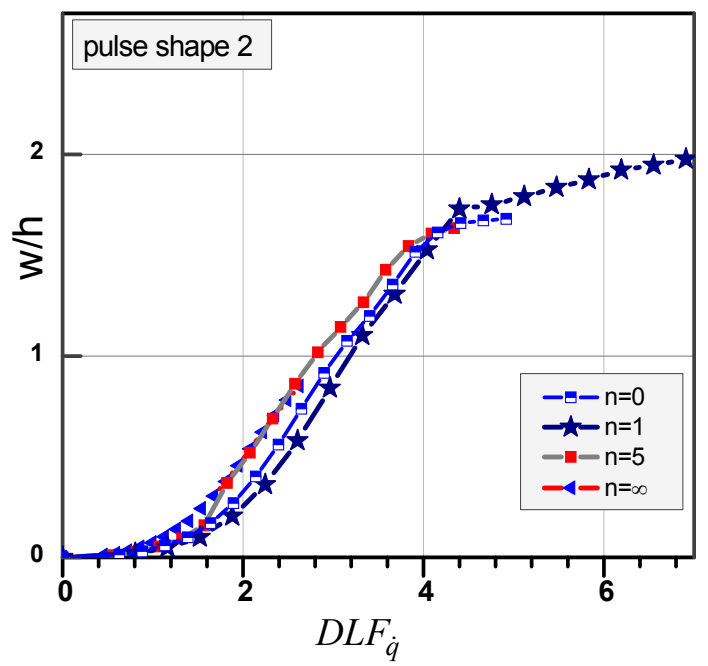

Fig.7. Maximal deflection of the plate versus a) dynamic heat flux load or b) $D L F_{\dot{q}}$ for different distribution indexes for shape 2 .

Table 2. Periods, critical values of temperatures for case 1.

\begin{tabular}{|c|c|c|c|c|c|c|c|c|c|c|}
\hline \multirow{2}{*}{$\begin{array}{c}\text { distribution } \\
\text { index } n\end{array}$} & \multirow{2}{*}{$\begin{array}{c}t_{0} \\
{[\mathrm{~ms}]}\end{array}$} & $\begin{array}{c}q_{c r}^{\text {static }} \\
{[\mathrm{MW}]}\end{array}$ & \multicolumn{2}{|c|}{ Pulse shape 1 } & \multicolumn{2}{c|}{ Pulse shape 2 } & \multicolumn{2}{|c|}{ Pulse shape 3 } & \multicolumn{2}{c|}{ Pulse shape 4 } \\
\cline { 4 - 13 } & $\dot{q}_{d y n}^{c r}$ & $D L F_{\dot{q}}^{c r}$ & $\begin{array}{c}\dot{q}_{d y n}^{c r} \\
{[\mathrm{MW}]}\end{array}$ & $D L F_{\dot{q}}^{c r}$ & $\begin{array}{c}\dot{q}_{d y n}^{c r} \\
{[\mathrm{MW}]}\end{array}$ & $D L F_{\dot{q}}^{c r}$ & $\begin{array}{c}\dot{q}_{d y n}^{c r} \\
{[\mathrm{MW}]}\end{array}$ & $D L F_{\dot{q}}^{c r}$ \\
\hline 0 & 11.6 & 79.3 & 78 & 0.98 & 220 & 2.77 & 220 & 2.77 & 560 & 7.1 \\
\hline 0.3 & 9.7 & 96.5 & 90 & 0.93 & - & - & - & - & 690 & 7.15 \\
\hline 1 & 8.13 & 111.4 & 120 & 0.98 & 320 & 2.87 & 320 & 2.87 & 910 & 8.19 \\
\hline 5 & 6.49 & 158.9 & - & - & 280 & 1.76 & 380 & 2.39 & 1260 & 7.92 \\
\hline$\infty$ & 5.46 & 221.0 & 190 & 0.9 & 550 & 2.61 & 550 & 2.61 & 1760 & 7.96 \\
\hline
\end{tabular}

a)

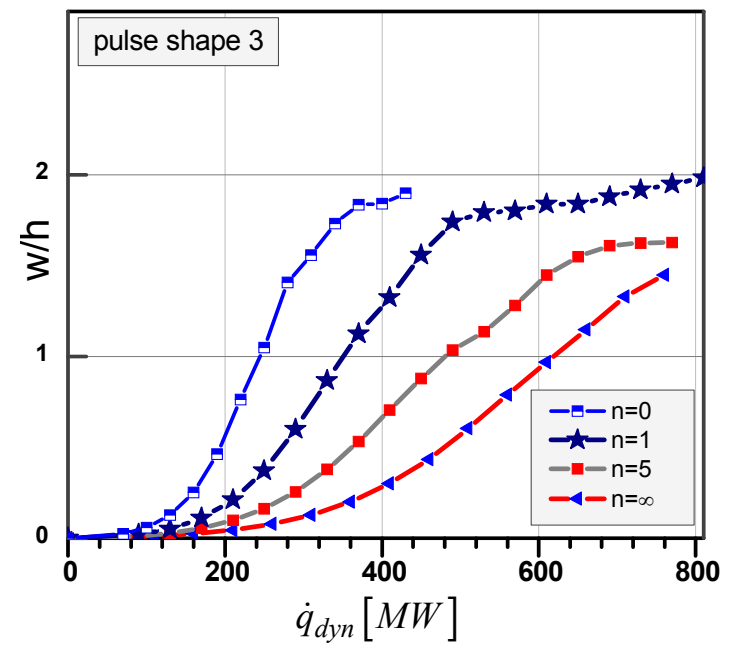

b)

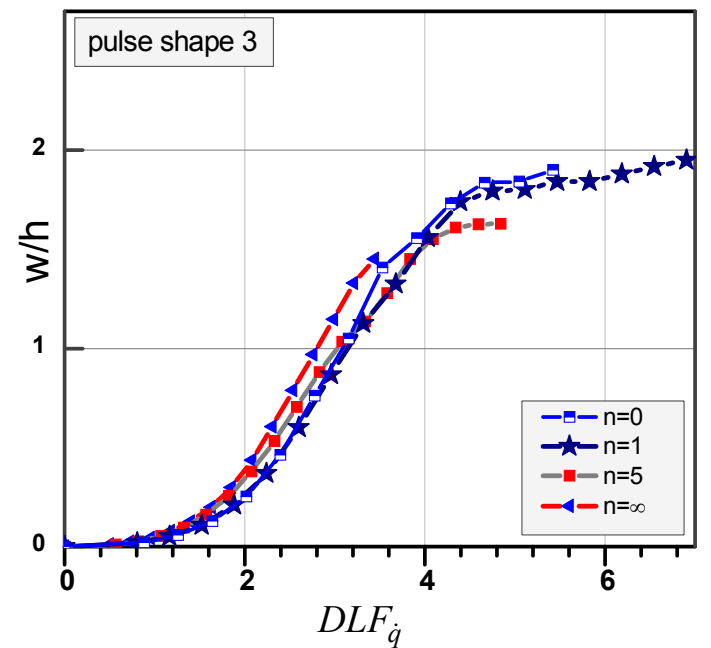

Fig.8. Maximal deflection of the plate versus a) dynamic heat flux load or b) $D L F_{\dot{q}}$ for different distribution indexes for shape 3 . 
However, one visible difference only appears for $n=5$ and in this case the critical heat fluxes amounted to $280 \mathrm{MW}$ and $380 \mathrm{MW}$, for pulse shape 2 and pulse shape 3, respectively. The discussed pulses ( 2 and 3 ) relate to a real pulse which the high-performance laser can produce. Substantially different results have been obtained for pulse 4 (isosceles triangle - Figs 9a and 9b). It turned out that this type of the pulse shape is the least dangerous because a rapid growth in the plate deflection occurs only just at $D L F_{\dot{q}}^{c r}$ equal, in dependence on volume fraction index, to values of $7.1 \div 8.19$.

a)

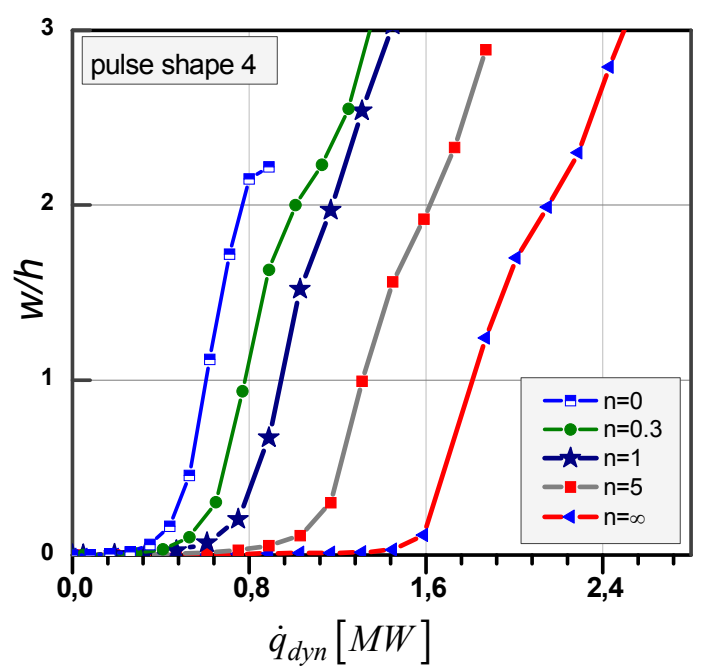

b)

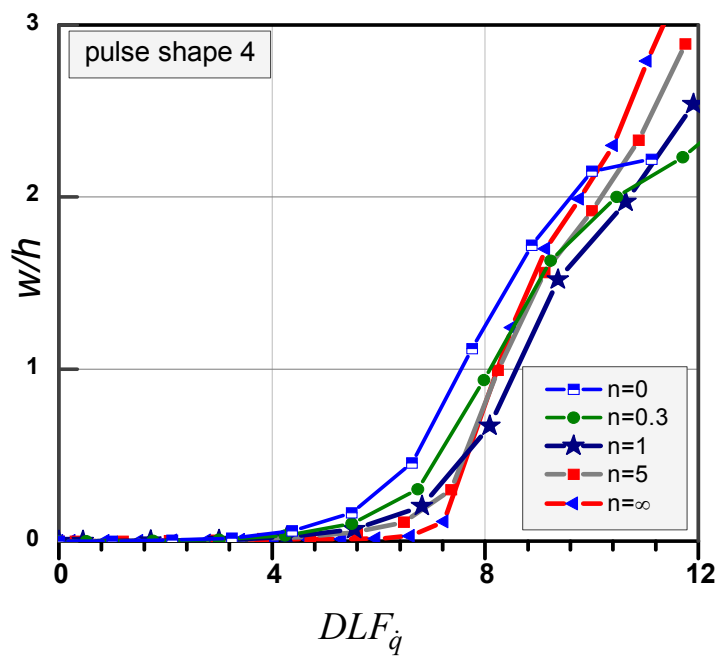

Fig.9. Maximal deflection of the plate versus a) dynamic heat flux load or b) $D L F_{\dot{q}}$ for different distribution indexes for shape 4.

Regarding case 4, all the curves differ from the curves determined for cases 1, 2, 3. Especially, it is easily seen that at some value of the heat flux, a sudden jump of the plate deflection follows. Moreover, observing the chart, with a further small increase of the heat flux pulse, deflections of the plate still rise to a great extent. A comparison of the plate response of all heat flux shapes for $n=1$ is shown in Fig. 10 .

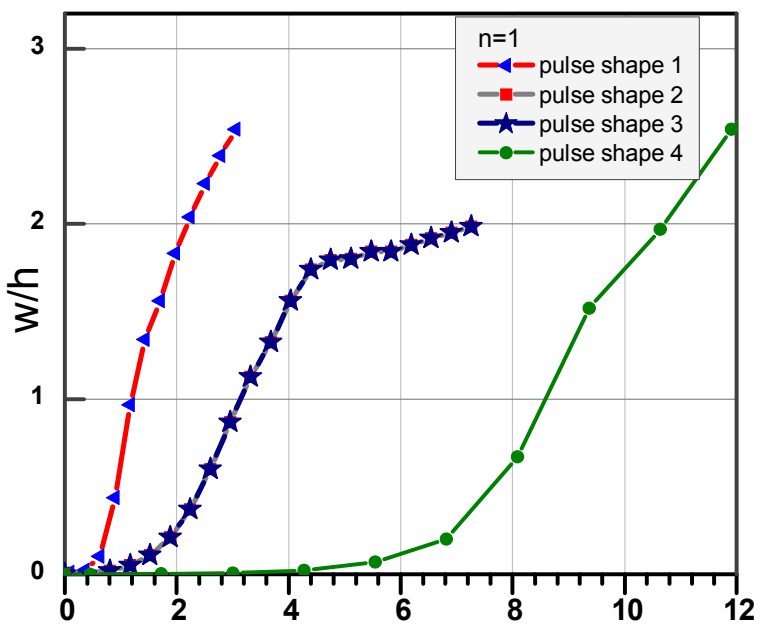

Fig.10. Comparison of the plate response for all assumed shapes for $n=1$. 
As was previously shown in Tab.2, the pulse shape 4 affects in the lowest degree $\left(D L F_{\dot{q}}^{c r}=8.19\right)$. The most dangerous still seems to be the rectangular one which delivers the energy two times greater (for this case $D L F_{\dot{q}}^{c r}=0.98$ ). The types 2 and 3 cause the same response of the plate as shown in Figs 7-8. In case 2 and case 3 it was noticed that $D L F_{\dot{q}}^{c r}=2.87$ (about three times greater than in case 1 and three times smaller than in case 4).

\section{Conclusions}

In this paper, numerical simulations of the heat flux action in a functionally graded plate based on the finite element method were pursued. Each plate underwent transient heat flux loads on one ceramic surface in time corresponding to a period of natural flexural vibrations for the considered volume fraction index. The main aim of this analysis was an evaluation of the plate behavior under real ultrahighperformance heat flux effect. It was concluded that, first of all, the volume fraction exponent plays a great role in the dynamic response of the plate. Another meaningful influence which can be considered resulted from the shape of the heat flux load.

\section{Acknowledgments}

The author of this paper would like to express his thanks to the National Science Centre of Poland for the financial support (2011/B/ST8/07441).

\section{Nomenclature}

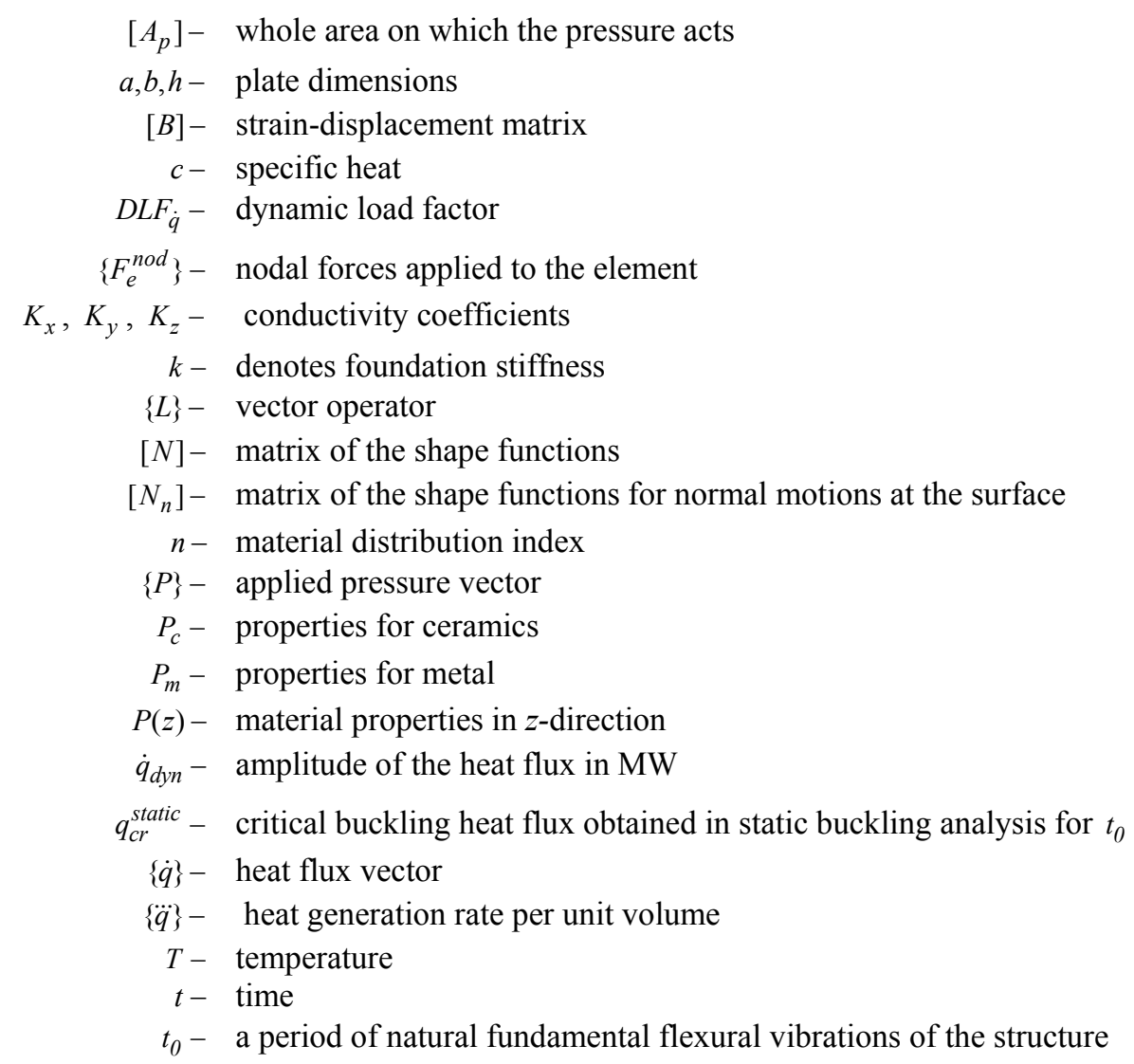




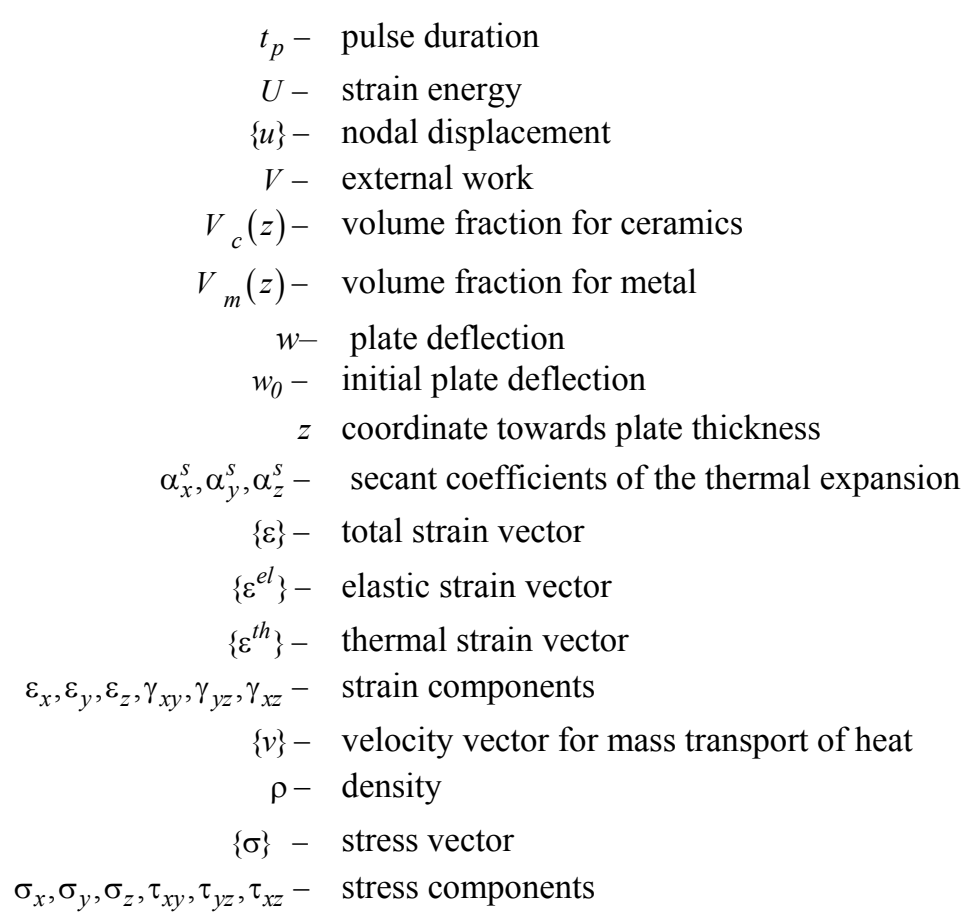

\section{References}

Bodaghi M. and Saidi A.R. (2010): Levy-type solution for buckling analysis of thick functionally graded rectangular plates based on the higher-order shear reformation plate theory. - Applied Mathematical Modeling, vol.34, pp.3659-3673.

Budiansky B. (1966): Dynamic buckling of elastic structures: Criteria and estimates. - Rep. SM-7, NASA, CR-66072.

Czechowski L. and Kowal-Michalska K. (2013): Static and dynamic buckling of rectangular functionally graded plates subjected to thermal loading. - Strength of Materials No.6, pp.45-55.

Documentation for Ansys 14.0 software

Hoang Van Tung and Nguyen Dinh Duc (2010): Nonlinear analysis of stability for functionally graded plates under mechanical and thermal loads. - Composites Structures, 92, pp.1184-1191.

Jankowski J. and Kowal-Michalska K. (2013): Dynamic response of FGM thin-walled plate structure subjected to a thermal pulse loading. - Theory and Applications, Faylor\&Francis Group, Londyn, Vol. pp. 297-320.

Javaheri R. and Eslami M.R. (2012): Thermal buckling of functionally graded plates based on higher order theory.Journal of Thermal Stresses, vol.25, pp.603-625.

Kowal-Michalska K. (Ed.) (2007): Dynamic Stability of Composite Plate Structures (in Polish). - Scientific-Technical Publisher, Warsaw.

Kowal-Michalska K. and Mania R. (2012): Static and dynamic buckling of FG plate subjected to thermomechanical loading. - Proceedings of Stability of Structures XIII-th Symposium, Zakopane, pp.373-382.

Mania R. (2011): Dynamic response of thin-walled structures, Statics, Dynamics and Stability of Structural Elements and Systems, pp. 51-71.

Mania R. and Kowal-Michalska K. (2007): Behavior of composite columns of closed cross-section under in-plane compressive pulse loading. - Thin-Walled Structures, vol.45, pp.902-905.

Na K.S. and Kim J.H. (2005): Thermal postbuckling investigations of functionally graded plates using 3-D finite element method. - Finite Elements in Analysis and Design, vol.42, pp.749-756. 
Praveen G.N. and Reddy J.N. (1998): Nonlinear transient thermoelastic analysis of functionally graded ceramic-metal plates. - Int. J. Solids Structures, vol.35, No.33, pp.4457-4476.

Samsam Shariat B.A., Javaheri R. and Eslami M.R. (2005): Buckling of imperfect functionally graded plates under inplane compressive loading. - Thin-Walled Structures, vol.43, pp.1020-1036.

Volmir S.A. (1972): Nonlinear dynamics of plates and shells (in Russian). - Science: Moscow.

Wu T.L., Shukla K.K. and Huang J.H. (2007): Post-buckling analysis of functionally graded rectangular plates. Composites Structures, vol.81, pp.1-10.

Received: July 7, 2014

Revised: January 26, 2015 